\title{
Utility of the trabecular bone score (TBS) in secondary osteoporosis
}

\author{
Fabio M. Ulivieri • Barbara C. Silva • \\ Francesco Sardanelli • Didier Hans • \\ John P. Bilezikian · Renata Caudarella
}

Received: 5 February 2014/Accepted: 25 April 2014/Published online: 23 May 2014

(C) Springer Science+Business Media New York 2014

\begin{abstract}
Altered bone micro-architecture is an important factor in accounting for fragility fractures. Until recently, it has not been possible to gain information about skeletal microstructure in a way that is clinically feasible. Bone biopsy is essentially a research tool. High-resolution peripheral Quantitative Computed Tomography, while non-invasive, is available only sparsely throughout the world. The trabecular bone score (TBS) is an imaging technology adapted directly from the Dual Energy X-Ray Absorptiometry (DXA) image of the lumbar spine. Thus, it is potentially readily and widely available. In recent years, a large number of studies have demonstrated that TBS is significantly associated with direct measurements of bone micro-architecture, predicts current and future fragility fractures in primary osteoporosis, and may be a useful
\end{abstract}

\section{F. M. Ulivieri}

Bone Metabolic Unit, Division of Nuclear Medicine, Fondazione Irccs Ca' Ospedale Maggiore Policlinico, Milan, Italy

\section{B. C. Silva · J. P. Bilezikian}

Metabolic Bone Diseases Unit, Division of Endocrinology,

Department of Medicine, College of Physicians and Surgeons,

Columbia University, New York, NY, USA

F. Sardanelli

Radiologiy Unit, IRCCS Policlinico San Donato, Department of Biomedical Sciences for Health, University of Milan, San

Donato Milanese, Milan, Italy

D. Hans $(\bowtie)$

Center of Bone Diseases, Division of Rheumatology,

Department of Bones and Joints, Lausanne University Hospital,

Avenue Pierre Decker 4, 1011 Lausanne, Switzerland

e-mail: didier.hans@chuv.ch

R. Caudarella

Maria Cecilia Hospital GVM Care and Research, Cotignola, RA, Italy adjunct to BMD for fracture detection and prediction. In this review, we summarize its potential utility in secondary causes of osteoporosis. In some situations, like glucocorticoid-induced osteoporosis and in diabetes mellitus, the TBS appears to out-perform DXA. It also has apparent value in numerous other disorders associated with diminished bone health, including primary hyperparathyroidism, androgen-deficiency, hormone-receptor positive breast cancer treatment, chronic kidney disease, hemochromatosis, and autoimmune disorders like rheumatoid arthritis. Further research is both needed and warranted to more clearly establish the role of TBS in these and other disorders that adversely affect bone.

Keywords Secondary osteoporosis - Trabecular bone score · Bone quality - Glucocorticoids - Primary hyperparathyroidism - Rheumatoid arthritis - Chronic kidney disease $\cdot$ Diabetes mellitus

$\begin{array}{ll}\text { Abbreviations } \\ \text { 2D } & \text { Two-dimensional } \\ \text { 3D } & \text { Three-dimensional } \\ \text { AUC } & \text { Area under the curve } \\ \text { BMD } & \text { Bone mineral density } \\ \text { BMI } & \text { Body mass index } \\ \text { Conn.D } & \text { Connectivity density } \\ \text { CT } & \text { Computed tomography } \\ \text { DXA } & \text { Dual energy X-ray absorptiometry } \\ \text { FEA } & \text { Finite element analysis } \\ \text { FEXI } & \text { Finite element analysis of X-ray images } \\ \text { FN } & \text { Femoral neck } \\ \text { GC } & \text { Glucocorticoids } \\ \text { LS } & \text { Lumbar spine } \\ \text { MRI } & \text { Magnetic resonance imaging } \\ \text { OR } & \text { Odds ratio }\end{array}$




$\begin{array}{ll}\text { ROC } & \text { Receiver operating characteristic } \\ \text { SD } & \text { Standard deviation } \\ \text { TBS } & \text { Trabecular bone score } \\ \text { TH } & \text { Total hip } \\ \text { Tb.N } & \text { Trabecular number } \\ \text { Tb.Sp } & \text { Trabecular spacing } \\ \text { Tb.Th } & \text { Trabecular thickness } \\ \text { WHO } & \text { World Health Organization }\end{array}$

\section{Introduction}

Osteoporosis is the most common and costly of all bone diseases [1-4], accounting for $\$ 34.8$ billion in direct health care costs per annum [5]. In the United States, it affects $\sim 10$ million individuals age 50 and above, with an additional 34 million considered to be "at risk" [6]. Each year worldwide, nine million new osteoporosis-related fractures are estimated to occur [7], two million of which occur in the United States alone [8]. Up to $10 \%$ of women in their fifties have already experienced an osteoporotic fracture [9]. Men are also commonly affected [10-12]. The hip and the spine fragility fracture, the most common sites, are associated with increased morbidity and, in some cases, increased mortality $[13,14]$. These sobering demographic figures are destined to increase with some experts predicting a doubling in fractures over the next 40-50 years [7].

Osteoporosis has traditionally been categorized as primary and secondary. Primary osteoporosis refers to osteoporosis occurring in a postmenopausal woman and/or in association with aging. Secondary osteoporosis is associated with a known underlying disease or medications. Approximately one-third of postmenopausal women, and one half of premenopausal women and men [5] suffer from secondary osteoporosis. The most common secondary causes of osteoporosis include long-term glucocorticoid (GC) therapy, inflammatory arthritides (like rheumatoid arthritis), hypogonadism in men, malabsorption syndromes, and primary hyperparathyroidism [15].

The measurement of bone mineral density (BMD) by dual energy X-ray absorptiometry (DXA) is the clinical basis for the diagnosis of osteoporosis [16]. However, while BMD is clearly one of the major determinants of bone strength and fracture risk [17], the assessment of fracture risk by BMD lacks sensitivity. In fact, more fragility fractures occur in osteopenic individuals ( $\mathrm{T}$-score between -2.5 and -1.0$)$ than in subjects with osteoporosis (T-score $<-2.5$ ) [18]. It is clear that factors in addition to BMD account for bone strength and fracture risk. They include bone geometry, micro-architecture, as well as micro-damage, mineralization, and turnover $[19,20]$. With specific reference to microstructure, standard DXA measurements give no insight.
The gold standard for the direct assessment of bone micro-architecture is histomorphometry of the transiliac crest bone biopsy. However, the transiliac bone biopsy is an invasive procedure and, moreover, does not necessarily reflect microstructure at sites that fracture. A number of non-invasive techniques have been developed recently to assess skeletal micro-architecture. These techniques include quantitative computed tomography (QCT) [21, 22], high-resolution peripheral quantitative computed tomography (HRpQCT) [23] and magnetic resonance imaging (MRI) [24], all of which allow for either direct or indirect measurement of bone micro-architecture. However, assessing bone micro-architecture using QCT, HRpQCT or MRI is costly and subjects the patient to another imaging procedure. Alternatively, adaptation of X-ray-based images, like plain radiographs, using gray-level textural features has been explored utilizing fractal dimension and Fourier analysis [25-30]. An ideal solution, in terms of practicality, costs and risks, would be adaptation of DXAbased images. In fact, DXA can now be used to identify existing vertebral fractures [31-34], to evaluate hip geometry and to estimate femoral strength [35-37]. Moreover, a new DXA-based measure that considers bone mineral distribution in the proximal femur, instead of just BMD, may be well suited to enhance standard densitometric evaluation as a predictor of hip fracture risk [38]. The latest development is the trabecular bone score (TBS), a new gray-level textural metric that can be extracted from the 2-dimensional lumbar spine DXA image to estimate trabecular microstructure.

TBS is a texture parameter related to bone microarchitecture that may provide skeletal information that is not captured from the standard BMD measurement. Based on experimental variograms of the projected DXA image, TBS has the potential to discern differences in 3-dimensional (3D) micro-architecture between 2-D DXA measurements that are similar to each other [39, 40] (Fig. 1). An elevated TBS value correlates with better skeletal texture (a reflection of better micro-architecture); a low TBS value correlates with weaker skeletal texture (a reflection of degraded micro-architecture). The relationship between TBS texture parameters and 3D micro-architecture parameters has been documented by several ex vivo studies that have reported significant correlations between TBS and various micro-structural parameters of bone assessed by micro-computed tomography [39, 41, 42].

From a practical standpoint, TBS can be applied retrospectively to previously acquired DXA images, without the need for further imaging and, obviously, can be compared directly with the same region of interest. Moreover, TBS estimates generally are robust and independent from the particular DXA instrument, as long as the device is properly calibrated [43]. This ability to assess TBS 
Bone Mineral Density images

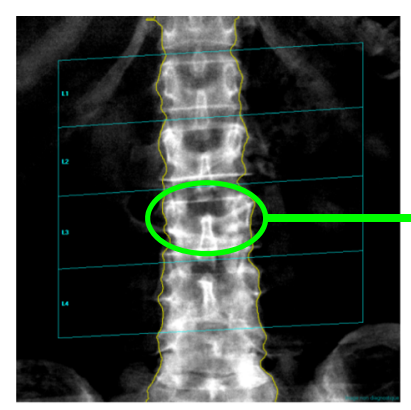

Illustration of a good

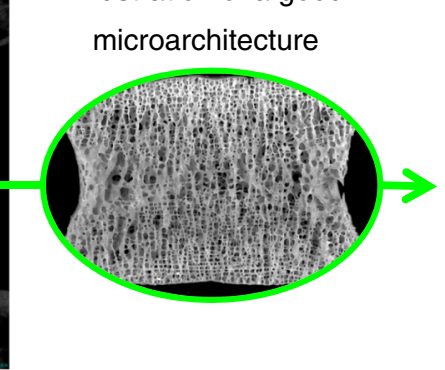

Identical BMD

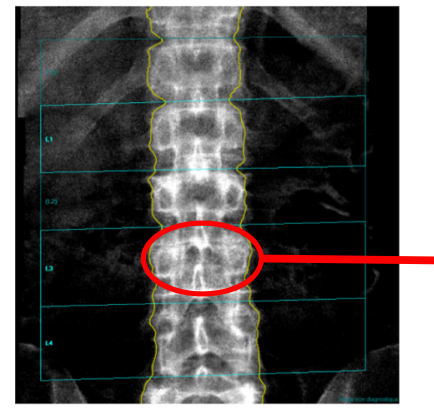

Illustration of a poor

microarchitecture

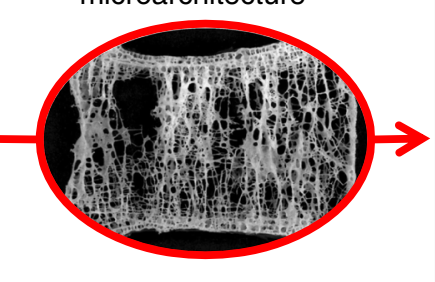

TBS Images and associated reference curves

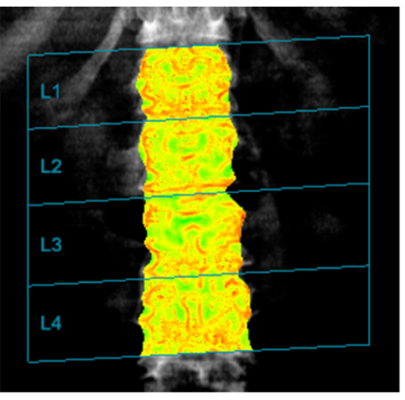

TBS L1-L4: 1.457

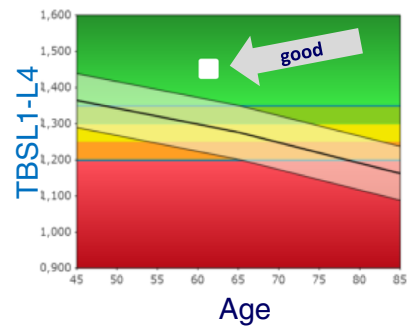

Fig. 1 Generating TBS for healthy versus osteoporotic bone

retrospectively using previously-obtained DXA images has been instrumental in the collection of empirical data validating its use in clinical practice.

Clinically, TBS has been shown to predict current and future fragility fractures in primary osteoporosis, to be a helpful adjunct to BMD and clinical risk factors for fracture detection and prediction, and for monitoring treatment effect. A detailed review of the use of TBS for the management of primary osteoporosis has been published elsewhere [40]. In addition, a number of studies have shown that TBS has value in secondary causes of osteoporosis. This is of interest, since in many of these conditions the measurement of BMD by DXA lacks sensibility to predict fracture risk. In cases of diabetes mellitus or long-term GC exposure, for examples, the increase in fracture risk is not governed by the expected relationship between BMD as determined by DXA and fracture risk [44-49]. Similarly, in asymptomatic primary hyperparathyroidism, trabecular bone as evaluated by lumbar spine DXA, is relatively well preserved [50]. This is in contrast to data from HRpQCT studies that have shown deteriorated trabecular microarchitecture, and epidemiological reports that provide evidence for the increased fracture risk at both vertebral and non-vertebral sites primary hyperparathyroidism [51-53]. While these unexpected findings between fracture risk and BMD by DXA could be related to alterations in bone

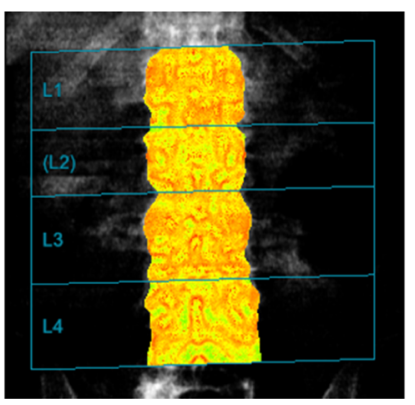

TBS L1-L4: 1.132

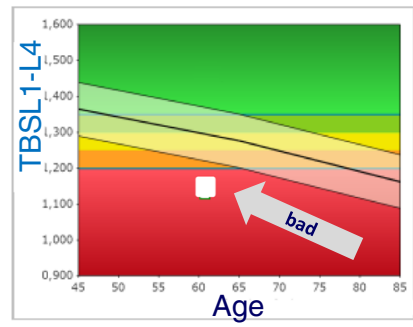

microstructure in the other etiologies for osteoporosis, current methods to assess bone microstructure are not widely available [54]. To this end, TBS has the potential to be used, in addition to BMD for fracture risk assessment in secondary osteoporosis. The primary objective of this report is to discuss the role of TBS in patients at risk for and diagnosed with secondary osteoporosis.

TBS predictions of current and future fragility fractures: primary osteoporosis

Most of the published research on TBS, to date, has been conducted in patients with presumed primary osteoporosis, or in whom risk factors for secondary osteoporosis were not considered in the analysis. In such studies, TBS has been shown to predict both current [55-64] and future/incident [65-68] fragility fractures. Additional studies have addressed the impact of efficacious therapies for osteoporosis on TBS measurements. While TBS is usually maintained or slightly improved in patients treated with bisphosphonates $[69,70]$, preliminary data have shown a significant increase in TBS in postmenopausal women treated with strontium [71], teriparatide [72], or denosumab [73]. More specifically, in terms of current fractures and within the context of crosssectional or retrospective studies, the TBS is consistently lower in postmenopausal women with a past osteoporotic 
fracture than in women without fractures. Several of these studies have shown that the TBS yields an incremental increase in the odds ratio (OR) for spine or hip fractures when combined with spine BMD [56-58, 65]. Moreover, preliminary cross-sectional observations in men also suggest that TBS is lower in men with vertebral fractures than in their non-fractured counterparts [59]. With respect to predicting fragility fracture risk prospectively, the TBS, across 4 independent prospective studies in postmenopausal women, has been shown to be at least as good as the BMD in predicting hip fractures [65], vertebral fractures [65, 68], and all fractures [65-67].

In terms of how the TBS responds to treatment, Krieg et al. [69] investigated the effects of antiresorptive agents (86\% bisphosphonates, $10 \%$ raloxifene, and $4 \%$ calcitonin) on the TBS in women age 50 and older. Relative to baseline, there was a significant improvement in BMD $(+1.86 \pm 1.8 \%$ per year), and a small increase in TBS $(+0.2 \pm 1.9 \%$ per year $)$ in treated women over a mean follow-up of 3.7-years. Significant reductions in mean BMD and the TBS were observed in women treated with placebo. Similarly, in subjects treated with zoledronic acid over a 3-year period, Popp et al. [70] observed a significant increase in mean BMD, and a lesspronounced but significant increase in TBS relative to baseline. In 79 postmenopausal women with osteoporosis randomized to receive either strontium $2 \mathrm{~g}$ /day or alendronate $70 \mathrm{mg} /$ week, Hans et al. [71].noted that spine TBS significantly increased by 2.3 and $3.1 \%$ over one and 2 years, respectively, in those on strontium, but not significantly (by 0.5 and $1.0 \%$, respectively) in those given alendronate. These findings are in agreement with previously observations indicating some benefit of strontium ranelate over alendronate in terms of enhancing bone architecture [74]. Günther et al. [72], in an open-labeled, multi-centre study, found that a 2-year treatment with recombinant 1-34 human parathyroid hormone (teriparatide) of postmenopausal women significantly increased spine TBS by $+4.3 \%$ and lumbar spine (LS) BMD by $+7.6 \%$. At 2 years, there was no correlation between the changes in BMD and TBS relative to baseline. Finally, in a subset of 285 women from the FREEDOM trial of denosumab, McClung et al. [73] observed significant increases in both TBS $(+2.4 \%)$ and $\operatorname{LS}-\mathrm{BMD}(+9.8 \%)$ relative to baseline in women treated with denosumab at $60 \mathrm{mg}$ every 6 months for 3 years. In contrast, declines in both TBS and BMD were noted among controls given placebo.

Trabecular bone score for secondary osteoporosis

As stated previously, secondary osteoporosis may arise either as a result of the effects of underlying disease or from medications (e.g., glucocorticoids). In fact, most of the time, secondary osteoporosis results from the combinations of risk factors and chronic diseases associated with their treatment. The impact of these risk factors, treatments and diseases on BMD is usually well documented, while studies demonstrating their impact on bone micro-architecture are much less common. Nevertheless, it is likely that bone micro-architecture plays an important role along with BMD. For example, the increase in fracture risk associated with glucocortoids (GC) occurs before major bone loss can be measured by DXA [47]. This observation could be related to GC-induced changes in bone microarchitecture [75]. Most of the studies that have been directed at TBS in the secondary osteoporoses are only available as abstracts at this time. The following sections summarize these data.

\section{Glucocorticoid-induced (GC) osteoporosis}

The therapeutic use of systemic GCs is one of the most common secondary causes of osteoporosis, responsible for an estimated $25 \%$ of all cases [76]. Even low-doses of prednisolone $(2.5-7.5 \mathrm{mg} /$ day $)$ or the equivalent are associated with an increase in the incidence of vertebral fractures, with higher doses increasing that risk [47]. Up to $50 \%$ of patients on long-term GC will sustain a fragility fracture [77].

GCs increase the risk of fractures in several ways [7780], which include decreasing the production of estrogen and testosterone, gonadotrophins, and reducing renal calcium reabsorption and GI calcium absorption in the gastrointestinal tract. They also cause proximal muscle wasting, which increases the risk of falls, especially among the elderly and those with inflammatory arthritic conditions like rheumatoid arthritis and systemic lupus erythematosis, for whom steroids are typically used. However, the greatest effects of GCs are on bone metabolism with the result being reduced bone quantity and quality. Reduced bone formation results from GC-induced inhibition of the differentiation and replication of osteoblasts, and the induction of osteoblast apoptosis. In addition, GCs cause an early transient increase in osteoclast lifespan, which increases bone resorption. Further adverse effects of GC that influence bone quality are increased osteocyte apoptosis and decreased skeletal angiogenesis, vascularity, and blood flow within canaliculae [77, 79, 80]. Glucocorticoids also augment the production of dickkopf-related protein 1 (DKK-1), an antagonist of the Wnt signaling pathway, and suppresses the expression of runt-related transcription factor-2 and bone morphogenetic protein, all of which cause bone formation to decline [78].

Colson et al. [81] studied changes in TBS in 136 GCtreated women, 45-80 years old, within a routine clinical practice setting. All patients were treated with GC in a dose equivalent to at least $5 \mathrm{mg}$ of prednisolone daily for one or more years. Glucocorticoid-treated patients demonstrated a 
significant $4.0 \%$ decrease in TBS relative to aged-matched healthy subjects $(p<0.0001)$, while no significant change in BMD was observed. Similar significant results were observed among those on very low GC doses $(<5 \mathrm{mg} /$ day; $-3.5 \%$ of TBS). Reduced TBS was evident irrespective of the level of BMD, with a significant decline in TBS of 5.7 and $2.9 \%$ in women with osteoporosis or osteopenia, respectively. These findings were even more marked when fracture status and number were taken into account. Among those without a fracture, GCs induced a $3.4 \%$ decline in TBS. In those who sustained an osteoporosis-related fracture, the decline in the TBS was much more marked: $-6.2 \%$ in those with osteoporosis-related vertebral fractures grade 2 or greater; $-4.6 \%$ in those with an osteoporosis-related fracture of any kind; and $-7.8 \%$ in those with 2 or more osteoporosis-related fractures. The ageadjusted OR for TBS was 1.60 (1.04-2.47) for any osteoporosis-related fracture and $1.62(1.02-2.59)$ for osteoporosis-related vertebral fractures. In contrast, no significant association between fracture risk and BMD was found.

Subsequently, Paggiosi et al. [82] assessed the ability of TBS to discriminate among (a) GC-treated women who had taken prednisolone $\geq 5 \mathrm{mg} /$ day (or the equivalent) for $>3$ months $(n=64)$, (b) women who had sustained a recent fracture of the distal forearm $(n=46)$, proximal humerus $(n=37)$, vertebra $(n=30)$ or proximal femur ( $n=28)$; and (c) healthy women $(n=371)$. While BMD and TBS were significantly lower in those with fractures than in healthy controls, TBS, but not BMD, was significantly lower in GC-treated women than in the control group $(p=0.0004)$. Although these studies are preliminary and involve a small number of patients, their results suggest that (1) TBS is reduced in patients on systemic GC treatment compared with normal controls, even when BMD measured by DXA is similar between the groups and (2) TBS may aid in the assessment of fracture risk in such patients.

\section{Cushing's disease}

Endogenous glucocorticoid excess associated with Cushing's syndrome results in bone loss that may affect trabecular bone more than cortical bone. The reduced BMD is often more pronounced at the lumbar spine, a skeletal site with a large component of trabecular bone, than at the femoral neck [83, 84]. Moreover, these patients have an increased risk for fragility fracture [85]. Several studies have identified improvement in bone mass in patients with Cushing's disease after treatment [84, 86]. One such study was conducted by Koumakis et al. [87], who examined treatment effects on BMD and on bone micro-architecture texture assessed by TBS in 11 patients with Cushing's disease (6 women/5 men; mean age 40 years; mean BMI
$28 \mathrm{~kg} / \mathrm{m}^{2}$, Mean 24-h urinary cortisol before treatment $957 \mu \mathrm{g} / 24 \mathrm{~h})$. Ten subjects underwent transsphenoidal pituitary surgery, while one received medical treatment alone; all patients experienced normalization of 24-h urinary cortisol with treatment. BMD and TBS increased, respectively, by 3.7 and $7.3 \%$ after 1 year, and by 7.9 and $13.5 \%$ after 2 years. BMD and TBS were not significantly correlated with each other before or after treatment. This was the first study to report bone recovery at the LS both in BMD and TBS in treated Cushing's disease.

\section{Adrenal incidentalomas}

Adrenal incidentalomas are an uncommon, although increasingly recognized, cause of subclinical hypercortisolism. As with manifestations of exogenous systemic GC and Cushing's disease, this excess in cortisol is associated with an increased risk of fracture, independent of BMD. Sparse information exists on the effects of these tumors on bone micro-architecture in humans. Eller-Vainicher et al. [88] investigated TBS in 102 patients with adrenal incidentaloma and subclinical hypercortisolism diagnosed in the presence of at least two of the following: (1) urinary free cortisol $>70 \mathrm{mg} / 24 \mathrm{~h}(193.1 \mathrm{nmol} / \mathrm{L})$; (2) cortisol after 1-mg dexamethasone suppression test (1-mg DST) $>3.0 \mathrm{mg} / \mathrm{dL}(82.8 \mathrm{nmol} / \mathrm{L})$; and (3) adrenocorticotropic hormone $(\mathrm{ACTH})<10 \mathrm{pg} / \mathrm{mL}(<2.2 \mathrm{pmol} / \mathrm{L})$. In these 102 patients and in 70 matched controls, BMD was measured by DXA at the LS, femoral neck (FN), and total hip (TH). The TBS was assessed at the LS. Vertebral deformities were assessed by plain radiographs. Patients with hypercortisolism $(n=34)$ had significantly lower LS-BMD $(-0.31 \pm 1.17), \quad$ FN-BMD $(-0.29 \pm 0.91)$, and TBS $(-3.18 \pm 1.21)$ than patients without hypercortisolism $(n=68,0.31 \pm 1.42,0.19 \pm 0.97$, and $-1.70 \pm 1.54)$ or controls $(0.42 \pm 1.52,0.14 \pm 0.76$, and $-1.19 \pm 0.99$, respectively). The presence of a fracture was significantly associated with a low TBS alone (OR 4.8; $95 \% \mathrm{CI}$ 1.85-12.42) and with a pattern of low TBS plus low LS-BMD (OR 4.37; 95 \%CI 1.71-11.4), after adjusting for age, BMI, and gender. Low TBS plus low LS-BMD exhibited good specificity $(79 \%)$ as a predictor of fractures, whereas normal TBS (i.e., >-1.5) plus normal LS-BMD was highly specific (88\%) for excluding fractures. Finally, TBS predicted the occurrence of a new fracture in 40 patients followed for 24 months (OR 11.2; 1.71-71.41; $p<0.012$ ) regardless of LS-BMD, BMI, or age.

These findings were echoed by Guglielmi et al. [89], who measured BMD and TBS in 33 Caucasian Italian women (mean age 61 years) with adrenal incidentalomas. Mean values for LS and TH BMD T-scores were -1.49 and -0.65 , respectively. Twenty-four percent of the subjects were osteoporotic, $80 \%$ exhibited hypogonadism, 
and $27 \%$ had subclinical hypercortisolism. Compared to age-matched TBS reference values, TBS was significantly lower in patients with adrenal incidentaloma, independent of the LS-BMD T-score classification. Incidentaloma subjects with hypogonadism exhibited a significantly lower LS-BMD and TBS than incidentaloma subjects without hypogonadism. In addition, compared to age-matched TBS reference values, TBS was significantly lower in subjects with adrenal incidentaloma associated with hypogonadism and with subclinical hypercortisolism. LS-BMD values in patients with adrenal incidentaloma and hypogonadism did not differ from the reference LS-BMD $(p>0.80)$. While this study is limited by the lack of a control group, these data suggest that bone texture as assessed by TBS is impaired in subjects with adrenal incidentaloma associate or not with hypogonadism or subclinical hypercortisolism.

\section{Primary hyperparathyroidism (PHPT)}

PHPT is a common endocrinopathy often accompanied by bone loss readily demonstrated by the evaluation of the BMD by DXA. In this disease, there is a typical pattern by DXA, with BMD frequently lowest at the distal $1 / 3$ radius, a skeletal site that is enriched in cortical bone, and highest at the LS, a site predominantly comprised of trabecular bone. Despite the relatively well-preserved trabecular bone by DXA, recent studies utilizing HRpQCT have shown that both trabecular and cortical compartments are abnormal in PHPT [53, 90]. Three independent groups have assessed TBS in patients with PHPT [91-93] and their results suggest that TBS may identify trabecular abnormalities not captured by LS-BMD in PHPT [91, 92].

Romagnoli et al. [91] compared 73 Caucasian postmenopausal women with PHPT and 74 age- and gender-matched, healthy controls. In all participants, LS-BMD, FN-BMD, and TH-BMD were measured by DXA and, in 67 patients and 34 controls, BMD was also measured at the distal third of the radius $(R)$. TBS was measured in the same region as LS-BMD. Spinal radiographs were obtained in all subjects. Mean TBS values were significantly reduced in PHPT $(1.19 \pm 0.10)$ relative to controls $(1.24 \pm 0.09$; $p=0.01$ ). Patients and controls were not different in age, years since menopause, BMI, 25(OH)D serum levels, creatinine clearance, LS-BMD, or FN-BMD. BMD at the TH and $1 / 3$ radius were significantly lower in PHPT patients than in controls. Within the PHPT group, subjects with vertebral fractures $(n=29 ; 24$ Grade 1,4 Grade 2 , and 1 Grade 3 ) had a significantly lower TBS than those without fractures $(n=44)(1.14 \pm 0.10$ vs. $1.22 \pm 0.10$, respectively; $p<0.01$ ), whose TBS values did not differ from controls. Mean TBS values in patients with $(n=18)$ and without $(n=55)$ non-vertebral fractures were not significantly different $(1.16 \pm 0.09$ vs. $1.20 \pm 0.11 ; p>0.05)$. In the PHPT group, vertebral fracture was associated with TBS (AUC: $0.716 ; 95 \%$ CI $0.590-0.841 ; p=0.002$ ), and with years since menopause (AUC: 0.717; $95 \%$ CI 0.595-0.840; $p=0.002)$. The presence of vertebral fractures was not associated with age, LS-BMD, or BMI. The combination of 'years since menopause $>10$ ' plus 'TBS $<1.2$ ' was significantly associated with a significant risk of vertebral fracture $(\mathrm{OR}=11.73)$.

Silva et al. [92] assessed TBS from spine DXA images in relation to high-resolution peripheral quantitative $\mathrm{CT}$ indices and bone stiffness at the distal radius and tibia in 22 postmenopausal women with PHPT. In this group, TBS was low with an average value of 1.240 , representing an abnormal trabecular pattern (normal $>1.35$ ). At the radius, TBS was significantly correlated with total $(r=0.49)$, cortical $(\mathrm{Ct}$; $r=0.51$ ), and trabecular volumetric BMD (Tb.vBMD; $r=0.48$ ), cortical thickness (Ct.Th; $r=0.45$ ), Tb.N $(r=0.51), \quad \mathrm{Tb} . \mathrm{Sp}(r=-0.49)$, trabecular heterogeneity (Tb.Sp SD; $r=-0.44)$, and whole bone stiffness $(r=0.44)$ ( $p<0.05$ for all associations). Significant correlations remained after controlling for body weight. At the tibia, TBS was associated with total $(r=0.62)$, Ct. $(r=0.47)$ and Tb.vBMD $(r=0.53)$, Ct.Th $(r=0.52)$, and whole bone stiffness $(r=0.52)(p<0.05$ for all). After adjusting for body weight, HRpQCT indices of trabecular micro-architecture were significantly correlated with TBS (Tb.N, $r=0.57$; Tb.Sp, $r=-0.52$; and Tb.Sp SD, $r=-0.48$ ). TBS was not correlated with total area, Tb.Th and trabecular stiffness at either site evaluated.

Maury et al. [94] reported on the effects of parathyroidectomy, evaluating the longitudinal evolution of spinal BMD and TBS parameters in 29 postmenopausal Caucasian women (mean age 62 years; mean body mass index $26 \mathrm{~kg} / \mathrm{m}^{2}$ ) with primary hyperparathyroidism (PHPT) before and 1 year after surgery. Before surgery, all patients had measurements of serum total and ionized calcium, phosphate, PTH, and C-telopeptide of type 1 collagen, as well of 24-h urine calcium and phosphate reabsorption rate. Before surgery, BMD and TBS were moderately correlated with each other, TBS explaining $45 \%$ of BMD; neither BMD nor TBS was correlated with any of the biological parameters. After surgery, BMD and TBS increased by $4.7 \pm 5.4$ and $1.6 \pm 4 \%$ respectively, with no correlation between gains in BMD and TBS. Pre-operative total serum calcium was significantly correlated with BMD gain 1 year post-surgery. No other correlations were identified between pre-operative biological parameters and post-treatment changes in either BMD or TBS. This preliminary study was the first to report data on changes in spine BMD and TBS, both assessed by DXA, in women with PHPT undergoing parathyroid surgery. Consistent with previously-published data, spine BMD increased after surgery, while TBS increased more slightly. This last result is consistent with 
what was published when iliac crest biopsies were analyzed longitudinally post-operatively; i.e., showing increased trabecular thickness and trabecular spaces.

Eller-Vainicher et al. [93] find that TBS is reduced in PHPT and associated with vertebral fracture and that it improves after surgery. In this prospective observational study, 92 patients with PHPT (74 females, age $62.7 \pm 10.1$ years) and 98 control subjects were evaluated at baseline, and in the prospective arm of the study, 20 PHPT subjects who underwent parathyroidectomy were compared with 10 conservatively treated PHPT patients after 24 months. Vertebral fractures were assessed by radiographs. At baseline, PHPT patients had significantly lower TBS and higher prevalence of vertebral fracture than controls. BMD was also lower in PHPT than in control group in all sites measured. TBS was associated with vertebral fracture (OR 1.4, $95 \% \mathrm{CI} 1.1-1.9, p=0.02)$, regardless of LS-BMD, age, BMI, and gender. In surgically treated patients, TBS, LS, TH, and FN-BMD increased significantly, whereas BMD and TBS seemed to remain stable in conservatively treated subjects.

Finally, Rolighed et al. [95] evaluated, using a randomized double-blind longitudinal study, the role of treatment with high dose of vitamin D3 in patients with PHPT and a reduced plasma concentration of 25-hydroxycholecalciferolon the safety and efficacy on calcium homeostasis and bone metabolism. The evaluation of changes in bone metabolism included the measurement of bone turnover biochemical markers, BMD and TBS before and after surgical treatment. Daily supplementation with 2800 IU cholecalciferol induced a significant increase in the concentration of $250 \mathrm{HD}$ before and after PTX $(p<0.001)$, as well as a significant reduction in PTH before PTX $(p<0.01)$ in the treated group compared to the placebo group. Likewise, in the treated group, lumbar spine BMD increased by $2.5 \%(p<0.01)$ and CTx were reduced by $22 \%(p<0.005)$ before PTX. After surgical treatment, the spine BMD increased in both groups, respectively of $2.6 \%$ in treated group and $3.7 \%$ in placebo group. Before and after PTX, the TBS score of the lumbar spine was similar in both groups, but when the patients were considered together, a significant increase in TBS was observed after PTX. The Authors conclude that the BMD response to supplementation with vitamin $\mathrm{D}$ can not be identified by TBS. and that "further studies are needed to evaluate the changes of an insufficient level of vitamin D on TBS."

\section{Treatment of hormone-receptor positive breast cancer}

Bone health is a relevant issue in women undergoing various hormonal and non-hormonal treatments for breast cancer, with fractures as common occurrence that significantly and adversely affects quality of life and even survival [96]. Recently, a small substudy of the randomized Tamoxifen Exemestane Adjuvant Multinational (TEAM) trial has determined the effects of the aromatase-inhibitor exemestane and the estrogen-receptor antagonist tamoxifen on LS-BMD and TBS in postmenopausal women with hormone-sensitive primary breast cancer [97]. Women were randomized to receive either tamoxifen $(n=17)$ or exemestane $(n=19)$. Compared to baseline, patients receiving tamoxifen had a mean increase in LS-BMD of $+1.0 \%,+1.5 \%$, and $+1.9 \%$, whereas patients receiving exemestane showed a mean decline of $-2.3,-3.6$, and $-5.3 \%$ at 6-, 12-, and 24-month treatment, respectively. TBS also increased by $+2.2,+3.5$, and $+3.3 \%$ in tamoxifen-treated subjects, while it decreased by -0.9 , -1.7 , and $-2.3 \%$ in exemestane-treated women at months 6,12 , and 24 , respectively. Changes in TBS from baseline were different between exemestane and tamoxifen at months 6 ( $p<0.05), 12(p<0.007)$, and $24(p<0.006)$. No significant correlations were evident between TBS and BMD for the spine or total hip, either at baseline or during follow-up

\section{Autoimmune disorders}

Several explanations account for the increased bone loss and fracture risk in subjects with autoimmune disorders, particularly in those with autoimmune arthritis like rheumatoid arthritis, ankylosing spondylitis, and systemic lupus erythematosus. As already discussed, they often require at least low-dose systemic corticosteroids early in the course of illness, while other, slower-acting disease-modifying treatments are being initiated, and later during disease flairs. Additional factors that may adversely affect bone mass and increase fracture risk include reduced physical exercise, reduced sun exposure leading to low serum levels of 25-hydroxyvitamin D, and proximal muscle wasting [5]. Patients with rheumatoid arthritis are especially prone to develop osteoporosis and fragility fractures. In rheumatoid arthritis and ankylosing spondylitis, bone mass has been extensively evaluated by measuring areal BMD with DXA; but few data exist for TBS. Breban et al. [98] studied the combination of TBS and BMD for vertebral fracture risk detection in subjects with rheumatoid arthritis with or without GC treatment. Their study involved 185 women, mean age $56 \pm 14$, with rheumatoid arthritis for an average of $15.5 \pm 9.9$ years; 112 were receiving GC (mean dose of $6.4 \pm 4.3 \mathrm{mg} /$ day), and 162 were on some other diseasemodifying drug. Vertebral fractures from T4 to L4 were evaluated using vertebral fracture assessment software on DXA. Vertebral fractures (grade $>1$ ) were detected in 33 (17.8\%) women. While BMD at the LS and femoral neck was not different between patients receiving GC and in 
those not taking GC, BMD at the total hip was significantly lower in patients currently on GC. Similarly, TBS was lower in patients currently on GC $(1.211 \pm 0.1161)$ than in those not receiving the $\operatorname{drug}(1.265 \pm 0.098 ; p<0.0001)$. Despite the low number of fractures, TBS was significantly lower in patients with vertebral fracture $(1.131 \pm 0.195)$ than in those without fractures (1.245 \pm 0.106 ; $p=0.0001)$. The area under the receiver operating characteristic (ROC) curve (AUC) for vertebral fracture risk prediction was 0.704 for TBS, and $0.621,0.727$, and 0.719 for BMD at the LS, total hip and femoral neck, respectively. A TBS threshold (1.173) was calculated that corresponded to the highest levels of sensitivity $(75 \%)$ and specificity (66\%) according to ROC curves for the detection of vertebral fracture.

In a case-control study, Toussirot et al. [99] evaluated TBS in patients with rheumatoid arthritis or ankylosing spondylitis (AS) relative to healthy controls. Changes in LS and hip BMD and TBS score during anti-tumor necrosis factor alpha treatment were also prospectively examined. In the case-control study, 30 patients with rheumatoid arthritis (American College of Rheumatology criteria, 19 females; 12 postmenopausal women; mean age 57 years; mean disease duration 12 years; 26 of them on low-dose corticosteroids) and 30 patients with AS (New York criteria, 27 males, mean age 44 years; mean disease duration 13 years; none on GC) were evaluated and compared to 50 healthy controls. LS-BMD and hip BMD were measured by DXA. TBS was calculated from L2 to L4 images and patients with rheumatoid arthritis had significantly lower BMD and T-scores at the hip than healthy subjects.Patients with with rheumatoid arthritis (RA) had lower BMD and T-score at the hip $(p<0.005)$ compared to healthy controls. Similarly, Hip T-score in patients with ankylosing spondylitis (AS) was also decreased $(p=0.02)$. LS-BMD did not differ between patients and controls. TBS was lower in RA and AS compared to controls: $1.242 \pm 0.16$ and $1.282 \pm 0.13$ versus $1.365 \pm 0.14$, respectively ( $p=0.005$ ).In the prospective phase of this study, a group of 20 patients treated with anti-tumor necrosis factor alpha (12 ankylosing spondylitis and 8 rheumatoid arthritis) were followed for 2 years: LS and hip BMD were increased at 24 months $(+6.3$ and $+2.4 \%$, respectively), significantly for the spine. Across the whole group, TBS did not change. However, in patients with rheumatoid arthritis, TBS significantly decreased, while in patients with ankylosin spondylitis, TBS remained stable. The TBS clearly was decreased in these two forms of inflammatory rheumatic disease, especially in rheumatoid arthritis. Long-term antitumor necrosis factor alpha treatment exerted a positive effect on LS bone mass, but had no influence on TBS. Contrary to ankylosing spondylitis, the TBS decreased in rheumatoid arthritis patients treated with anti-tumor necrosis factor alpha, suggesting that this drug exerts different influences on bone.

\section{Sex steroids}

In adult males, both bone mass and levels of gender-related steroids appear to decline slowly with age. The role of androgens on the age-related decline in BMD remains controversial in males. Mascarenhas et al. [100] evaluated the relationship between testosterone levels and LS TBS, and BMD at the LS and femoral neck in 80 healthy adult men (mean age 54 years). Weak but significant correlations were identified between LS TBS and serum total testosterone $(r=0.24 ; p=0.03)$ and the free androgen index ( $r=0.23 ; p=0.04)$. In addition to the clear influence that female hormones have, total testosterone levels may play a role in determining bone quality in terms of TBS.

\section{Chronic kidney disease}

End-stage renal disease is a well-established risk factor for reduced $\mathrm{BMD}$ and osteoporosis, as well as for hip fracture [101-103]. The utility of measuring BMD with DXA in patients with chronic kidney disease remains unclear, since BMD can be high, low or, normal. Moreover, very limited data exist concerning the effects of chronic kidney disease on bone micro-architecture, particularly in the axial skeleton. Bone biopsy studies at the iliac crest have demonstrated micro-structural alterations in both the trabecular and cortical compartments in these patients. Leib et al. [104] measured LS TBS in 47 non-Hispanic white women with chronic kidney disease (mean age 56 years and mean BMI $26 \mathrm{~kg} / \mathrm{m}^{2}$ ), compared to 94 healthy age- and BMImatched women. Twenty-one percent of subjects had exposure to GC, $3.4 \%$ had thyroid disease, and $17 \%$ had experienced at least one low-energy fracture. Seventy-three percent of all subjects were postmenopausal women. The correlation between spine TBS and BMD was significant $(r=0.48)$, whereas spine TBS and BMI were not significantly associated $(r=0.08)$. Subjects with chronic kidney disease had a significantly lower TBS, whereas spine BMD was borderline $(p=0.054)$. Among subjects with chronic kidney disease, those with a fracture had a significant lower TBS, whereas no difference was seen for BMD. Also in subjects with chronic kidney disease, TBS was associated with the presence of a fracture with an OR per SD decrease in TBS of 2.5 and AUC of 0.756. Using multivariate logistic regression via backward selection, chronic kidney disease was significantly associated with TBS and a maternal history of hip fracture; meanwhile, BMD, steroids, smoking, and a family history of osteoporosis were ultimately excluded. The OR per SD decrease in TBS was 4.67 after adjusting for a maternal history of hip fracture. 
Table 1 Summary of a main fully published studies regarding TBS and Secondary Osteoporosis

\begin{tabular}{|c|c|c|c|c|c|c|c|c|}
\hline \multicolumn{9}{|c|}{ TBS and secondary osteoporosis } \\
\hline Disease & Author & Year & Study design & $\begin{array}{l}\text { Patients } \\
\text { no. }\end{array}$ & $\begin{array}{l}\text { Control } \\
\text { no. }\end{array}$ & Main findings & Observation & $\begin{array}{l}\text { Correlation TBS } \\
\text { versus spine BMD }\end{array}$ \\
\hline \multicolumn{9}{|c|}{ Hyperparathyroidism } \\
\hline 1 & $\begin{array}{l}\text { Eller- } \\
\text { Vainicher } \\
\text { C }\end{array}$ & 2013 & $\begin{array}{l}\text { Cross sectional } \\
\text { and } \\
\text { longitudinal }\end{array}$ & 92 & 98 & $\begin{array}{l}\text { TBS is associated with VFx (OR } \\
1.495 \% \text { CI 1.1-1.9). Low TBS } \\
\text { plus low FN-BMD show } 71.7 \% \\
\text { of accuracy in detecting pts at } \\
\text { risk of fracture with cut off as } \\
-2,0 \text { for TBS, }-0.3 \text { for LS, } \\
-0.2 \text { for TH and }-0.6 \text { for FN. } \\
\text { Low TBS and low TBS plus low } \\
\text { FN-BMD show respectively, for } \\
\text { detecting VFxPHPT, SN } 75 \% \text {; } \\
\text { SP } 61.5 \%, \text { ACC } 67.4 \% \text {; SN } \\
52.5 \% \text { SP } 86.5 \% \text { ACC } \\
71.7 \% \text {. The surgically treated } \\
\text { pts show a significant Tbs } \\
\text { improvement ( }-3.03 \pm 1,17 \text { vs. } \\
-1.63 \pm 0.37), \text { significantly } \\
\text { higher than LS, FN, TH. In } \\
\text { conservatively treated pts with } \\
\text { incident VFx, TBS decreases } \\
\text { respect to pts without, while } \\
\text { BMD changes are not } \\
\text { significant }\end{array}$ & $\begin{array}{l}\text { BMD values of cases and controls } \\
\text { (mean age } 62 \text { years) are } \\
\text { expressed as Z-score. TBS data } \\
\text { are reported as Z-score in } \\
\text { relation to the French reference } \\
\text { population }\end{array}$ & $r=0.27 ; p=0.011$ \\
\hline 2 & $\begin{array}{l}\text { Romagnoli } \\
\text { E }\end{array}$ & 2013 & Cross sectional & 73 & 74 & $\begin{array}{l}\text { Tbs is reduced in PTHpts and in } \\
\text { those with VF.Tbs }<1.2 \text { plus } \\
\text { YSM }>10 \text { show a } 11.73 \text { OR } \\
\text { (CI } 2.43-66.55) . \text { Tbs }<1.2 \\
\text { shows a negative predictive } \\
\text { value in VF detecting of } 81.2\end{array}$ & $\begin{array}{l}\text { TBS value significantly lower in } \\
\text { patients than in controls } \\
(p<0.01)\end{array}$ & na \\
\hline 3 & Silva BC & 2013 & Cross sectional & 22 & 0 & $\begin{array}{l}\text { Tbs correlates with tibia and } \\
\text { radius HRpQCT } \\
\left(0.23<r^{2}<0.38 \text { for radius and }\right. \\
0.23<r^{2}<0.44 \text { for Tibia). Tbs } \\
\text { correlates with a BMD third } \\
\text { radius }(r=0.427 ; p=0.047) \\
\text { and UD radius }(r=0.45 ; \\
p=0.036)\end{array}$ & & $r=0.367 ; p=\mathrm{NS}$ \\
\hline 4 & Rolighed L & 2014 & Longitudinal & 23 & 23 & $\begin{array}{l}\text { TBS increased significantly } \\
\text { following PTX in the entire } \\
\text { population }(2.8 \%, p<0.05) \\
\text { but without significant } \\
\text { differences between } \mathrm{w} \text { and wo } \\
\text { vitamin D groups }\end{array}$ & $\begin{array}{l}\text { BMD response to vitamin D } \\
\text { supplementation could not be } \\
\text { detected by TBS }\end{array}$ & na \\
\hline \multicolumn{9}{|c|}{ Diabetes mellitus } \\
\hline 1 & Leslie WD & 2013 & Retrospective & 2356 & 27051 & $\begin{array}{l}\text { LS-Tbs is reduced in DMpts and it } \\
\text { is BMD-independent predictor } \\
\text { of fractures (aHR: } 1.27 \text {, CI } \\
1.110-1.46 \text { ). TBS aOR for the } \\
\text { lowest tertile: } 2.61, \text { CI } 2.3-2.97 \\
\text { while BMD aOR }<1\end{array}$ & $\begin{array}{l}\text { All BMD measurements wre } \\
\text { significantly greater in women } \\
\text { with than without diabetes } \\
(p<0.001) . \text { In contrast, mean } \\
\text { lumbar spine TBS was lower in } \\
\text { the diabetic than non diabetic } \\
\text { women }(p<0.001)\end{array}$ & na \\
\hline \multicolumn{9}{|c|}{ Treatment of hormone-receptor positive breast cancer } \\
\hline 1 & Kalder M & 2013 & $\begin{array}{l}\text { head to head } \\
\text { (TAM vs. } \\
\text { EXE) }\end{array}$ & 17 & 19 & $\begin{array}{l}\text { TBS TAM is lower than TBS } \\
\text { EXE }(1273 \pm 0.109 \text { vs. } \\
1341 \pm 0.084) \text {. At } 24 \text { mo } \\
\text { versus baseline TBS EXE } \\
-2.3 \% \pm 1.1 \text { while TBS TAM } \\
3.3 \pm 1.6\end{array}$ & & $r=0.25 ; p=0.05$ \\
\hline
\end{tabular}


Table 1 continued

\begin{tabular}{|c|c|c|c|c|c|c|c|c|}
\hline \multicolumn{9}{|c|}{ TBS and secondary osteoporosis } \\
\hline Disease & Author & Year & Study design & $\begin{array}{l}\text { Patients } \\
\text { no. }\end{array}$ & $\begin{array}{l}\text { Control } \\
\text { no. }\end{array}$ & Main findings & Observation & $\begin{array}{l}\text { Correlation TBS } \\
\text { versus spine BMD }\end{array}$ \\
\hline \multicolumn{9}{|c|}{ Adrenal incidentalomas } \\
\hline 1 & $\begin{array}{l}\text { Eller- } \\
\text { Vainicher } \\
\text { C }\end{array}$ & 2012 & $\begin{array}{l}\text { Prospective } \\
\text { observational } \\
\text { study }\end{array}$ & $\begin{array}{l}102(34 \\
\text { wSH; } \\
68 \\
\text { woSH) }\end{array}$ & 70 & $\begin{array}{l}\text { Low TBS is associated with the } \\
\text { presence of fr (OR 4.8; } 95 \% \text { CI } \\
1.85-12.42, p=0.001) \text {. The } \\
\text { presence of fr is also associated } \\
\text { with the cluster low TBS plus } \\
\text { low LS-BMD (OR 4.37, } \\
95 \% \text { CI } 1.71-11.4, p=0.002) \text {. } \\
\text { Low TBS plus LS-BMD show a } \\
\text { good SP (79 \%) for predicting } \\
\text { fractures. The combination of } \\
\text { TBS and LS-BMD is useful to } \\
\text { identify pts with and without } \\
\text { SH. The cutoff with the best } \\
\text { compromise between Sn and Sp } \\
\text { is TBS: - } 1.5 \text { and BMD: }-0.0 \\
\text { (Low TBS: SN } 81.4 \% \text {; Sp } \\
53.5 \% \text {, ACC } 69.6 \% \\
p<0.0001 ; \text { Low TBS plus low } \\
\text { LS-BMD: Sn } 50.8 \%, \text { SP } \\
79.1 \% \text {, ACC } 62.7 \%, p \text { 0.002) }\end{array}$ & $\begin{array}{l}\text { BMD values of cases (pts wSH/ } \\
\text { woSH) and controls (mean age } \\
67 \text { years) are expressed as } \\
\text { Z-score. TBS data are reported } \\
\text { as Z-score in relation to the } \\
\text { reference population. The } \\
\text { combination of TBS and LS- } \\
\text { BMD is useful to identify pts } \\
\text { wSH and woSH at risk for VF }\end{array}$ & $r=0.27 ; p=0.007$ \\
\hline \multicolumn{9}{|c|}{ Autoimmune disorders } \\
\hline 1 & Bréban S & 2012 & cross sectional & 185 & 60 & $\begin{array}{l}\text { T-scores are significantly lower in } \\
\text { pts with VF than in pts without } \\
\text { VF, difference at femoral neck } \\
(p=0.0001) \text {. Also TBS is } \\
\text { significantly lower in RA pts } \\
\text { with VF than without VF } \\
(1.131 \pm 0.195 \text { vs. } \\
1.245 \pm 0.106, p=0.0001) . \\
\text { The threshold of } 1.173 \text { for TBS } \\
\text { has the best SN and SP, } \\
\text { respectively } 63 \% \text { and } \\
74 \%) \text {.TBS has a better } \\
\text { discrimination value than LS- } \\
\text { BMD for prediction of presence } \\
\text { of VF in pts with RA. }\end{array}$ & $\begin{array}{l}\text { RA woman with VF were } \\
\text { significantly older than those } \\
\text { without VF }(p=0.0004)\end{array}$ & $\begin{array}{l}r=0.58, p<0.0001 \\
\quad \text { for RA whole pop; } \\
r=0.52, p=0.003 \\
\text { for RA wVF; } \\
r=0.41, \\
p=0.0001 \text { for RA } \\
\text { woVF }\end{array}$ \\
\hline
\end{tabular}

$F N$ femoral neck BMD, $S n$ sensitivity, $S p$ specificity, $T A M$ tamoxifen, EXE exemestane, $S H$ subclinical hypercortisolism, $f r$ fracture, $A C C$ accuracy, $w$ with, $w o$ without, $P T X$ parathyroidectomy

The investigators concluded that, in the LS, chronic kidney disease exerts a negative effect on TBS, but no clear effect on BMD. This study demonstrated, for the first time, impaired axial trabecular micro-architectural texture in those with CKD.

\section{Hemochromatosis}

Hemochromatosis is a relatively common genetic disease that causes chronic systemic iron overload. Hemochromatosis creates a state of hyper-intestinal iron absorption. Homozygous and heterozygous forms exist. In the homozygous form, overload may be massive in various organs and become life-threatening. The impact of hemochromatosis on bone is known, with osteoporosis identified in 25-34\% of individuals with the homozygous form, with a controversial impact on trabecular texture. Chapuis et al. [105]. studied 15 women and 22 men with hemochromatosis type 1 (mean age and BMI were $56.8 \pm 12.6$ years and
$25.8 \pm 4.0 \mathrm{~kg} / \mathrm{m}^{2}$,respectively). Ferritin and transferrin saturation were $107.8 \pm 90.9 \mu \mathrm{g} / \mathrm{dl}$ and $42.5 \pm 12.4 \%$. Fifty-seven percent of patients were homozygous, and $11 \%$ of subjects had a T-score $\leq-2.5$ in the spine or femur. A low, but significant correlation between TBS and L1-L4 BMD was apparent for the entire population $(r=0.41$, $p=0.012$ ). No significant correlations were observed between iron load, ferritin, and bone parameters. In homozygous patients, a significant positive correlation was noted between iron load and BMD at any site $(0.48<r<0.57$, $p<0.03)$ and between iron load and TBS $(r=0.48$, $p=0.028)$. A significant positive correlation was also observed between total hip BMD and serum ferritin $(r=0.50, p=0.035)$. In homozygous males, a significant correlation was apparent between iron load and TBS $(r=0.800, p<0.01)$, but not between iron load and L1-L4 BMD. No significant differences were observed between homozygous and heterozygous subjects for iron load or BMD. However, TBS was significantly lower in 
heterozygous than in homozygous subjects $(p=0.025)$. Based upon these results, TBS could have a role in the assessment of bone health among hemochromatosis patients, though further investigations are clearly needed.

Diabetes mellitus

Type 2 diabetes is associated with an increased fracture risk, but paradoxically greater BMD. Leslie et al. evaluated the ability of LS TBS to account for increased fracture risk in diabetics within a large retrospective cohort study conducted in the province of Manitoba, Canada [106]. They initially screened 29,407 women $\geq 50$ years with baseline DXA, among whom 2,356 had diagnosed diabetes. Diabetes was associated with higher BMD at all sites, but lower LS TBS in both unadjusted and adjusted models. The adjusted OR for measurements in the lowest versus highest tertile was less than 1.00 for BMD, but was significantly increased for LS TBS (adjusted OR 2.61). During a mean follow-up of 4.7 years, major osteoporotic fractures were identified in 175 women (7.4\%) with diabetes and in 1,493 $(5.5 \%)$ without diabetes, with a significant difference between the groups. LS TBS was a BMD-independent predictor of fracture, and predicted fractures in those with diabetes, as well as in those without diabetes (adjusted hazard ratio 1.27 and 1.31, respectively). The effect of diabetes on fracture was reduced when LS TBS was added to a regression model, but was paradoxically increased by adding BMD measurements. In conclusion, in this one study, LS TBS was clearly more sensitive than BMD to the influence of diabetes. LS TBS was able to predict osteoporotic fractures in those with diabetes, and captured a larger portion of the diabetes-associated fracture risk than BMD.

\section{Conclusions}

This article reviewed the potential utility of TBS to evaluate the bone texture in individuals with conditions or diseases related to increased fracture risk (a summary can be found in Table 1). Data in patients with secondary osteoporosis, while much less extensive and mostly published in abstract form, suggest that TBS may also be useful for fracture risk assessment in subjects with factors that predispose to bone loss. In fact, despite the relative small number of patients evaluated, TBS has been shown to be associated with fractures in diabetes, primary hyperparathyroidism, rheumatoid arthritis, adrenal incidentaloma, chronic kidney disease, and in individuals on longterm GC therapy. Moreover, TBS is reduced in patients with ankylosing spondylitis, and improves after the treatment of endocrinological conditions related to reduced bone mass, such as Cushing's disease, and primary hyperparathyroidism. Further research is needed to further define the promising role of the TBS in these and other disorders that adversely affect bone.

Conflict of interest Didier Hans is co-owner of the TBS patent and has corresponding ownership shares in medimaps group. All the other authors have no conflict of interest.

\section{References}

1. E. Czerwiński, J.E. Badurski, E. Marcinowska-Suchowierska, J. Osieleniec, Current understanding of osteoporosis according to the position of the World Health Organization (WHO) and International Osteoporosis Foundation. Ortop. Traumatol. Rehabil. 9, 337-356 (2007)

2. J.A. Kanis, O. Johnell, A. Oden, H. Johansson, E. McCloskey, FRAX and the assessment of fracture probability in men and women from the UK. Osteoporos. Int. 19, 385-397 (2008)

3. P.J. Meunier, P.D. Delmas, R. Eastell, M.R. McClung, S. Papapoulos, R. Rizzoli, E. Seeman, R.D. Wasnich, Diagnosis and management of osteoporosis in postmenopausal women: clinical guidelines. International Committee for Osteoporosis Clinical Guidelines. Clin. Ther. 21, 1025-1044 (1999)

4. A.C. Looker, E.S. Orwoll, C.C. Johnston, R.L. Lindsay, H.W. Wahner, W.L. Dunn, M.S. Calvo, T.B. Harris, S.P. Heyse, Prevalence of low femoral bone density in older U.S. adults from NHANES III. J. Bone Miner. Res. 12, 1761-1768 (1997)

5. K. Walker-Bone, Recognizing and treating secondary osteoporosis. Nat. Rev. Rheumatol. 8, 480-492 (2012)

6. Department of Health and Human Services, R.: The frequency of bone disease in Bone health and Osteoporosis: a Report of the Surgeon General. Office of the Surgeon General (US) (2004)

7. O. Johnell, J.A. Kanis, An estimate of the worldwide prevalence and disability associated with osteoporotic fractures. Osteoporos. Int. 17, 1726-1733 (2006)

8. R. Burge, B. Dawson-Hughes, D.H. Solomon, J.B. Wong, A. King, A. Tosteson, Incidence and economic burden of osteoporosis-related fractures in the United States, 2005-2025. J. Bone Miner. Res. 22, 465-475 (2007)

9. K.M. Davies, M.R. Stegman, R.P. Heaney, R.R. Recker, Prevalence and severity of vertebral fracture: the Saunders County Bone Quality Study. Osteoporos. Int. 6, 160-165 (1996)

10. W.D. Leslie, L.M. Lix, L. Langsetmo, C. Berger, D. Goltzman, D.A. Hanley, J.D. Adachi, H. Johansson, A. Oden, E. McCloskey, J.A. Kanis, Construction of a FRAX ${ }^{\circledR}$ model for the assessment of fracture probability in Canada and implications for treatment. Osteoporos. Int. 22, 817-827 (2011)

11. R.A. Adler, The need for increasing awareness of osteoporosis in men. Clin. Cornerstone 8(Suppl 3), S7-S13 (2006)

12. R.A. Adler, Osteoporosis in men: recent progress. Endocrine 44, 40-46 (2013)

13. W.S. Browner, A.R. Pressman, M.C. Nevitt, S.R. Cummings, Mortality following fractures in older women. The study of osteoporotic fractures. Arch. Intern. Med. 156, 1521-1525 (1996)

14. E.L. Hannan, J. Magaziner, J.J. Wang, E.A. Eastwood, S.B. Silberzweig, M. Gilbert, R.S. Morrison, M.A. McLaughlin, G.M. Orosz, A.L. Siu, Mortality and locomotion 6 months after hospitalization for hip fracture: risk factors and risk-adjusted hospital outcomes. JAMA 285, 2736-2742 (2001) 
15. A. Polymeris, K. Michalakis, V. Sarantopoulou, Secondary osteoporosis: an endocrinological approach focusing on underlying mechanisms. Endocr. Regulat. 47, 137-148 (2013)

16. Assessment of fracture risk and its application to screening for postmenopausal osteoporosis. Report of a WHO Study Group. World Health Organization technical report series. 843, 1-129 (1994)

17. L.D. Hordon, M. Raisi, J.E. Aaron, S.K. Paxton, M. Beneton, J.A. Kanis, Trabecular architecture in women and men of similar bone mass with and without vertebral fracture: I. Two-dimensional histology. Bone 27, 271-276 (2000)

18. O. Johnell, J.A. Kanis, A. Oden, H. Johansson, C. De Laet, P. Delmas, J.A. Eisman, S. Fujiwara, H. Kroger, D. Mellstrom, P.J. Meunier, L.J. Melton, T. O'Neill, H. Pols, J. Reeve, A. Silman, A. Tenenhouse, Predictive value of BMD for hip and other fractures. J. Bone Miner. Res. 20, 1185-1194 (2005)

19. T.M. Link, S. Majumdar, Current diagnostic techniques in the evaluation of bone architecture. Curr. Osteoporos. Rep. 2, 47-52 (2004)

20. C.D. Rubin, Emerging concepts in osteoporosis and bone strength. Curr. Med. Res. Opin. 21, 1049-1056 (2005)

21. H.K. Genant, K. Engelke, S. Prevrhal, Advanced CT bone imaging in osteoporosis. Rheumatology (Oxford, England) 47(Suppl 4), iv9-iv16 (2008)

22. M.A. Bredella, M. Misra, K.K. Miller, I. Madisch, A. Sarwar, A. Cheung, A. Klibanski, R. Gupta, Distal radius in adolescent girls with anorexia nervosa: trabecular structure analysis with highresolution flat-panel volume CT. Radiology 249, 938-946 (2008)

23. A.M. Cheung, J.D. Adachi, D.A. Hanley, D.L. Kendler, K.S. Davison, R. Josse, J.P. Brown, L.-G. Ste-Marie, R. Kremer, M.C. Erlandson, L. Dian, A.J. Burghardt, S.K. Boyd, Highresolution peripheral quantitative computed tomography for the assessment of bone strength and structure: a review by the Canadian Bone Strength Working Group. Curr. Osteoporos. Rep. 11, 136-146 (2013)

24. R. Krug, J. Carballido-Gamio, S. Banerjee, A.J. Burghardt, T.M. Link, S. Majumdar, In vivo ultra-high-field magnetic resonance imaging of trabecular bone microarchitecture at $7 \mathrm{~T}$. JMRI 27, 854-859 (2008)

25. P. Caligiuri, M.L. Giger, M.J. Favus, H. Jia, K. Doi, L.B. Dixon, Computerized radiographic analysis of osteoporosis: preliminary evaluation. Radiology 186, 471-474 (1993)

26. J. Samarabandu, R. Acharya, E. Hausmann, K. Allen, Analysis of bone X-rays using morphological fractals. IEEE Trans. Med. Imaging 12, 466-470 (1993)

27. S. Prouteau, G. Ducher, P. Nanyan, G. Lemineur, L. Benhamou, D. Courteix, Fractal analysis of bone texture: a screening tool for stress fracture risk? Eur. J. Clin. Invest. 34, 137-142 (2004)

28. J.S. Gregory, A. Stewart, P.E. Undrill, D.M. Reid, R.M. Aspden, Identification of hip fracture patients from radiographs using Fourier analysis of the trabecular structure: a cross-sectional study. BMC Med. Imaging 4, 4 (2004)

29. D. Chappard, P. Guggenbuhl, E. Legrand, M.F. Baslé, M. Audran, Texture analysis of X-ray radiographs is correlated with bone histomorphometry. J. Bone Miner. Metab. 23, 24-29 (2005)

30. T.J. Vokes, M.L. Giger, M.R. Chinander, T.G. Karrison, M.J. Favus, L.B. Dixon, Radiographic texture analysis of densitometergenerated calcaneus images differentiates postmenopausal women with and without fractures. Osteoporos. Int. 17, 1472-1482 (2006)

31. S.L. Bonnick, Bone densitometry in clinical practice: application and interpretation (Humana Press, New Jersey, 2009)

32. H.K. Genant, C.Y. Wu, C. van Kuijk, M.C. Nevitt, Vertebral fracture assessment using a semiquantitative technique. J Bone Miner Res 8, 1137-1148 (1993)
33. F. Duboeuf, D.C. Bauer, R.D. Chapurlat, J.M.P. Dinten, P. Delmas, Assessment of vertebral fracture using densitometric morphometry. J. Clin. Densitom 8, 362-368 (2005)

34. K.G. Faulkner, S.R. Cummings, D. Black, L. Palermo, C.C. Glüer, H.K. Genant, Simple measurement of femoral geometry predicts hip fracture: the study of osteoporotic fractures. J. Bone Miner. Res. 8, 1211-1217 (1993)

35. T.J. Beck, C.B. Ruff, K.E. Warden, W.W. Scott, G.U. Rao, Predicting femoral neck strength from bone mineral data. A structural approach. Investig. Radiol. 25, 6-18 (1990)

36. T. Nakamura, C.H. Turner, T. Yoshikawa, C.W. Slemenda, M. Peacock, D.B. Burr, Y. Mizuno, H. Orimo, Y. Ouchi, C.C. Johnston, Do variations in hip geometry explain differences in hip fracture risk between Japanese and white Americans? J. Bone Miner. Res. 9, 1071-1076 (1994)

37. C.M. Langton, S. Pisharody, J.H. Keyak, Comparison of 3D finite element analysis derived stiffness and BMD to determine the failure load of the excised proximal femur. Med. Eng. Phys. 31, 668-672 (2009)

38. H.F. Boehm, T. Vogel, A. Panteleon, D. Burklein, H. Bitterling, M. Reiser, Differentiation between post-menopausal women with and without hip fractures: enhanced evaluation of clinical DXA by topological analysis of the mineral distribution in the scan images. Osteoporos. Int. 18, 779-787 (2007)

39. D. Hans, N. Barthe, S. Boutroy, L. Pothuaud, R. Winzenrieth, M.-A. Krieg, Correlations between trabecular bone score, measured using anteroposterior dual-energy X-ray absorptiometry acquisition, and 3-dimensional parameters of bone microarchitecture: an experimental study on human cadaver vertebrae. J. Clin. Densitom. 14, 302-312 (2011)

40. B.C. Silva, W.D. Leslie, H. Resch, O. Lamy, O. Lesnyak, N. Binkley, E.V. McCloskey, J.A. Kanis, J.P. Bilezikian, Trabecular bone score: a non-invasive analytical method based upon the DXA image. J. Bone Miner. Res. (2014)

41. R. Winzenrieth, F. Michelet, D. Hans, Three-dimensional (3D) microarchitecture correlations with $2 \mathrm{D}$ projection image graylevel variations assessed by trabecular bone score using highresolution computed tomographic acquisitions: effects of resolution and noise. J. Clin. Densitom. 16, 287-296 (2012)

42. J.P. Roux, J. Wegrzyn, S. Boutroy, M.L. Bouxsein, D. Hans, R. Chapurlat, The predictive value of trabecular bone score (TBS) on whole lumbar vertebrae mechanics: an ex vivo study. Osteoporos. Int. 24, 2455-2460 (2013)

43. D. Krueger, J. Libber, N. Binkley, Trabecular bone score (TBS) comparability between GE lunar prodigy and iDXA densitometers and short-term TBS precision. Osteoporos. Int. 24(1), S364 (2013)

44. C. Di Somma, M. Rubino, A. Faggiano, L. Vuolo, P. Contaldi, N. Tafuri, N. Tafuto, M. Andretti, S. Savastano, A. Colao, Spinal deformity index in patients with type 2 diabetes. Endocrine 43, 651-658 (2013)

45. M.R. Rubin, Type 2 diabetes and fractures: more information is needed. Endocrine 43, 469-471 (2013)

46. A. Scillitani, G. Mazziotti, C. Di Somma, S. Moretti, A. Stigliano, R. Pivonello, A. Giustina, A. Colao, Treatment of skeletal impairment in patients with endogenous hypercortisolism: when and how? Osteoporos. Int. 25, 441-446 (2014)

47. J.A. Kanis, H. Johansson, A. Oden, O. Johnell, C. de Laet, L.J. Melton III, A. Tenenhouse, J. Reeve, A.J. Silman, H.A.P. Pols, J.A. Eisman, E.V. McCloskey, D. Mellstrom, A meta-analysis of prior corticosteroid use and fracture risk. J. Bone Miner. Res. 19, 893-899 (2004)

48. E.S. Strotmeyer, J.A. Cauley, A.V. Schwartz, M.C. Nevitt, H.E. Resnick, D.C. Bauer, F.A. Tylavsky, N. de Rekeneire, T.B. Harris, A.B. Newman, Nontraumatic fracture risk with diabetes mellitus and impaired fasting glucose in older white and black 
adults: the health, aging, and body composition study. Arch. Intern. Med. 165, 1612-1617 (2005)

49. G. Mazziotti, J. Bilezikian, E. Canalis, D. Cocchi, A. Giustina, New understanding and treatments for osteoporosis. Endocrine 41, 58-69 (2012)

50. S.J. Silverberg, E. Shane, L. de la Cruz, D.W. Dempster, F. Feldman, D. Seldin, T.P. Jacobs, E.S. Siris, M. Cafferty, M.V. Parisien, Skeletal disease in primary hyperparathyroidism. J. Bone Miner. Res. 4, 283-291 (1989)

51. P. Vestergaard, L. Mosekilde, Fractures in patients with primary hyperparathyroidism: nationwide follow-up study of 1201 patients. World J. Surg. 27, 343-349 (2003)

52. E. Vignali, G. Viccica, D. Diacinti, F. Cetani, L. Cianferotti, E. Ambrogini, C. Banti, R. Del Fiacco, J.P. Bilezikian, A. Pinchera, C. Marcocci, Morphometric vertebral fractures in postmenopausal women with primary hyperparathyroidism. J. Clin. Endocrinol. Metab. 94, 2306-2312 (2009)

53. E.M. Stein, B.C. Silva, S. Boutroy, B. Zhou, J. Wang, J. Udesky, C. Zhang, D.J. McMahon, M. Romano, E. Dworakowski, A.G. Costa, N. Cusano, D. Irani, S. Cremers, E. Shane, X.E. Guo, J.P. Bilezikian, Primary hyperparathyroidism is associated with abnormal cortical and trabecular microstructure and reduced bone stiffness in postmenopausal women. J. Bone Miner. Res. 28, 1029-1040 (2013)

54. J.F. Griffith, H.K. Genant, New advances in imaging osteoporosis and its complications. Endocrine 42, 39-51 (2012)

55. L. Pothuaud, N. Barthe, M.-A. Krieg, N. Mehsen, P. Carceller, D. Hans, Evaluation of the potential use of trabecular bone score to complement bone mineral density in the diagnosis of osteoporosis: a preliminary spine BMD-matched, case-control study. J. Clin. Densitom. 12, 170-176 (2009)

56. B. Rabier, A. Héraud, C. Grand-Lenoir, R. Winzenrieth, D. Hans, A multicentre, retrospective case-control study assessing the role of trabecular bone score (TBS) in menopausal Caucasian women with low areal bone mineral density (BMDa): analysing the odds of vertebral fracture. Bone 46, 176-181 (2010)

57. R. Winzenrieth, R. Dufour, L. Pothuaud, D. Hans, A retrospective case-control study assessing the role of trabecular bone score in postmenopausal Caucasian women with osteopenia: analyzing the odds of vertebral fracture. Calcif. Tissue Int. 86, 104-109 (2010)

58. L.M. Del Rio, R. Winzenrieth, C. Cormier, S. Di Gregorio, Is bone microarchitecture status of the lumbar spine assessed by TBS related to femoral neck fracture? A Spanish case-control study. Osteoporos. Int. 24, 991-998 (2013)

59. E. Leib, R. Winzenrieth, B. Aubry-Rozier, D. Hans, Vertebral microarchitecture and fragility fracture in men: a TBS study. Bone 62, 51 (2013)

60. F. Colson, R. Winzenrieth, D. Hans, Assessment of osteopenic women microarchitecture with and without osteoporotic fracture by TBS on a new generation bone densitometer. J. Clin. Densitom. 14, 169 (2011)

61. E. Leib, O. Lamy, R. Winzenrieth, D. Hans, Assessment of women microarchitecture with and without osteoporotic fracture by TBS on white non Hispanic US women. J. Clin. Densitom. 16, 268 (2013)

62. J. Vasic, T. Petranova, V. Povoroznyuk, C.G. Barbu, M. Karadzic, F. Gojkovic, J. Elez, R. Winzenrieth, D. Hans, V. Culaficvojinovic, C. Poiana, N. Dzerovych, R. Rashkov, A. Dimic, Evaluating spine micro-architectural texture (via TBS) discriminates major osteoporotic fractures from controls both as well as and independent of site matched BMD: the Eastern European TBS study. J. Bone Miner. Metab. 60, 185 (2013)

63. O. Lamy, M. Metzger, M.-A. Krieg, B. Aubry-Rozier, D. Stoll, D. Hans, OsteoLaus: prediction of osteoporotic fractures by clinical risk factors and DXA, IVA and TBS. Revue médicale suisse. 7, 2130, 2132-4, 2136 (2011)

64. D. Krueger, E. Fidler, J. Libber, B. Aubry-Rozier, D. Hans, N. Binkley, Spine trabecular bone score subsequent to bone mineral density improves fracture discrimination in women. J. Clin. Densitom. 16, 374 (2013)

65. D. Hans, A.L. Goertzen, M.-A. Krieg, W.D. Leslie, Bone microarchitecture assessed by TBS predicts osteoporotic fractures independent of bone density: the Manitoba study. J. Bone Miner. Res. 26, 2762-2769 (2011)

66. S. Boutroy, D. Hans, E. Sornay-Rendu, N. Vilayphiou, R. Winzenrieth, R. Chapurlat, Trabecular bone score improves fracture risk prediction in non-osteoporotic women: the OFELY study. Osteoporos. Int. 24, 77-85 (2013)

67. A.W. Popp, S. Meer, M.-A. Krieg, R. Perrelet, D. Hans, K. Lippuner, Bone mineral density (BMD) combined with microarchitecture parameters (TBS) significantly improves the identification of women at high risk of fracture: the SEMOF cohort study. Osteoporos. Int. 23, S327-S328 (2012)

68. M. Iki, J. Tamaki, E. Kadowaki, Y. Sato, N. Dongmei, R. Winzenrieth, S. Kagamimori, Y. Kagawa, H. Yoneshima, Trabecular bone score (TBS) predicts vertebral fractures in Japanese women over 10 years independently of bone density and prevalent vertebral deformity: the Japanese population-based osteoporosis (JPOS) cohort study. J. Bone Miner. Res. 29, 399 (2013)

69. M.A. Krieg, B. Aubry-Rozier, D. Hans, W.D. Leslie, Effects of anti-resorptive agents on trabecular bone score (TBS) in older women. Osteoporos. Int. 24, 1073-1078 (2013)

70. A.W. Popp, S. Guler, O. Lamy, C. Senn, H. Buffat, R. Perrelet, D. Hans, K. Lippuner, Effects of zoledronate versus placebo on spine bone mineral density and microarchitecture assessed by the trabecular bone score in postmenopausal women with osteoporosis: a three-year study. J. Bone Miner. Res. 28, 449-454 (2013)

71. D. Hans, M.-A. Krieg, O. Lamy, D. Felsenberg, Beneficial effects of strontium ranelate compared to alendronate on trabecular bone score in post menopausal osteoporotic women. a 2-year study. Osteoporos. Int. 23, S266-S267 (2012)

72. B. Günther, A.W. Popp, D. Stoll, Beneficial effect of PTH on spine BMD and microarchitecture (TBS) parameters in postmenopausal women with osteoporosis. A 2-year study. Osteoporos. Int. 23, s85-s386 (2012)

73. M.R. McClung, K. Lippuner, M.L. Brandi, J.-M. Kaufman, J.R. Zanchetta, M.-A. Krieg, H.G. Bone, R. Chapurlat, D. Hans, A. Wang, J. Yun, C. Zapalowski, C. Libanati, In postmenopausal women with osteoporosis, denosumab significantly improved trabecular bone score (TBS), an index of trabecular microarchitecture. Arthritis Rheum. 64, S832-S832 (2012)

74. R. Rizzoli, R.D. Chapurlat, J.-M. Laroche, M.A. Krieg, T. Thomas, I. Frieling, S. Boutroy, A. Laib, O. Bock, D. Felsenberg, Effects of strontium ranelate and alendronate on bone microstructure in women with osteoporosis. Results of a 2-year study. Osteoporos. Int. 23, 305-315 (2012)

75. D. Chappard, E. Legrand, M.F. Basle, P. Fromont, J.L. Racineux, A. Rebel, M. Audran, Altered trabecular architecture induced by corticosteroids: a bone histomorphometric study. J. Bone Miner. Res. 11, 676-685 (1996)

76. R. Eastell, D.M. Reid, J. Compston, C. Cooper, I. Fogelman, R.M. Francis, D.J. Hosking, D.W. Purdie, S.H. Ralston, J. Reeve, R.G. Russell, J.C. Stevenson, D.J. Torgerson, A UK Consensus Group on management of glucocorticoid-induced osteoporosis: an update. J. Int. Med. 244, 271-292 (1998)

77. R.S. Weinstein, Glucocorticoid-induced bone disease. New Engl. J. Med. 365, 62-70 (2011)

78. R.S. Weinstein, Glucocorticoids, osteocytes, and skeletal fragility: the role of bone vascularity. Bone 46, 564-570 (2010) 
79. C.A. O’Brien, D. Jia, L.I. Plotkin, T. Bellido, C.C. Powers, S.A. Stewart, S.C. Manolagas, R.S. Weinstein, Glucocorticoids act directly on osteoblasts and osteocytes to induce their apoptosis and reduce bone formation and strength. Endocrinology 145, 1835-1841 (2004)

80. L.C. Hofbauer, C. Hamann, P.R. Ebeling, Approach to the patient with secondary osteoporosis. Eur. J. Endocrinol. 162, 1009-1020 (2010)

81. F. Colson, B. Rabier, E. Vignon, Trabecular bone microarchitecture alteration in glucocorticoid treated women in clinical routine: a TBS evaluation. J. Bone Miner. Res. 25, 452 (2009)

82. M. Paggiosi, R. Eastell, The impact of glucocorticoid therapy on trabecular bone score in older women. J. Bone Miner. Res. 27, 21 (2012)

83. I. Chiodini, V. Carnevale, M. Torlontano, S. Fusilli, G. Guglielmi, M. Pileri, S. Modoni, A. Di Giorgio, A. Liuzzi, S. Minisola, M. Cammisa, V. Trischitta, A. Scillitani, Alterations of bone turnover and bone mass at different skeletal sites due to pure glucocorticoid excess: study in eumenorrheic patients with Cushing's syndrome. J. Clin. Endocrinol. Metab. 83, 1863-1867 (1998)

84. C. Kristo, R. Jemtland, T. Ueland, K. Godang, J. Bollerslev, Restoration of the coupling process and normalization of bone mass following successful treatment of endogenous Cushing's syndrome: a prospective, long-term study. Eur. J. Endocrinol. 154, 109-118 (2006)

85. P. Vestergaard, J. Lindholm, J.O.L. Jørgensen, C. Hagen, H.C. Hoeck, P. Laurberg, L. Rejnmark, K. Brixen, L.Ø. Kristensen, U. Feldt-Rasmussen, L. Mosekilde, Increased risk of osteoporotic fractures in patients with Cushing's syndrome. Eur. J. Endocrinol. 146, 51-56 (2002)

86. G. Luisetto, M. Zangari, V. Camozzi, M. Boscaro, N. Sonino, F. Fallo, Recovery of bone mineral density after surgical cure, but not by ketoconazole treatment, in Cushing's syndrome. Osteoporos. Int. 12, 956-960 (2001)

87. E. Koumakis, R. Winzenrieth, L. Guignat, C. Cormier, Cushing disease: restoration of bone mass and microarchitecture after hypercortisolism normalization. Osteoporos. Int. 23, S691 (2012)

88. C. Eller-Vainicher, V. Morelli, F.M. Ulivieri, S. Palmieri, V.V. Zhukouskaya, E. Cairoli, R. Pino, A. Naccarato, A. Scillitani, P. Beck-Peccoz, I. Chiodini, Bone quality, as measured by trabecular bone score in patients with adrenal incidentalomas with and without subclinical hypercortisolism. J. Bone Miner. Res. 27, 2223-2230 (2012)

89. G. Guglielmi, M. Nasuto, R. Winzenrieth, D. Hans, Evaluation of adrenal incidentaloma effects at axial skeleton on bone mass (BMD) and bone microarchitectural texture (TBS). Osteoporos. Int. 24, S315 (2013)

90. S. Hansen, J.-E. BeckJensen, L. Rasmussen, E.M. Hauge, K. Brixen, Effects on bone geometry, density, and microarchitecture in the distal radius but not the tibia in women with primary hyperparathyroidism: a case-control study using HR-pQCT. J. Bone Miner. Res. 25, 1941-1947 (2010)

91. E. Romagnoli, C. Cipriani, I. Nofroni, C. Castro, M. Angelozzi, A. Scarpiello, J. Pepe, D. Diacinti, S. Piemonte, V. Carnevale, S. Minisola, "Trabecular Bone Score" (TBS): an indirect measure of bone micro-architecture in postmenopausal patients with primary hyperparathyroidism. Bone 53, 154-159 (2013)

92. B.C. Silva, S. Boutroy, C. Zhang, D.J. McMahon, B. Zhou, J. Wang, J. Udesky, S. Cremers, M. Sarquis, X.-D.E. Guo, D. Hans, J.P. Bilezikian, Trabecular bone score (TBS): a novel method to evaluate bone microarchitectural texture in patients with primary hyperparathyroidism. J. Clin. Endocrinol. Metab. 98, 1963-1970 (2013)

93. C. Eller-Vainicher, M. Filopanti, S. Palmieri, F.M. Ulivieri, V. Morelli, V.V. Zhukouskaya, E. Cairoli, R. Pino, A. Naccarato, U. Verga, A. Scillitani, P. Beck-Peccoz, I. Chiodini, Bone quality, as measured by trabecular bone score, in patients with primary hyperparathyroidism. Eur. J. Endocrinol. 169, 155-162 (2013)

94. E. Maury, R. Winzenrieth, J. Souberbielle, C. Cormier, BMD and TBS micro architecture parameters assessment at spine in patients with primary hyperparathyroidism (PHPT) before and one year after parathyroidectomy. J. Bone Miner. Res. 25, S82S135 (2010)

95. L. Rolighed, L. Rejnmark, T. Sikjaer, L. Heickendorff, P. Vestergaard, L. Mosekilde, P. Christiansen, Vitamin D treatment in primary hyperparathyroidism: a randomized placebo controlled trial. J. Clin. Endocrinol. Metab. [Epub ahead of print] (2014)

96. T. Becker, L. Lipscombe, S. Narod, C. Simmons, G.M. Anderson, P.A. Rochon, Systematic review of bone health in older women treated with aromatase inhibitors for early-stage breast cancer. J. Am. Geriatr. Soc. 60, 1761-1767 (2012)

97. M. Kalder, D. Hans, I. Kyvernitakis, O. Lamy, M. Bauer, P. Hadji, Effects of exemestane and tamoxifen treatment on bone texture analysis assessed by tbs in comparison with bone mineral density assessed by DXA in women with breast cancer. J. Clin. Densitom [Article in Press] (2013)

98. S. Bréban, K. Briot, S. Kolta, S. Paternotte, M. Ghazi, J. Fechtenbaum, C. Roux, Identification of rheumatoid arthritis patients with vertebral fractures using bone mineral density and trabecular bone score. J. Clin. Densitom. 15, 260-266 (2012)

99. E. Toussirot, L. Mourot, D. Wendling, G. Dumoulin, Trabecular bone score in rheumatoid arthritis and ankylosing spondylitis and changes during long term treatment with TNFa blocking agents. J. Bone Miner. Res. 27, 381 (2012)

100. M.R. Mascarenhas, A.P. Barbosa, A. Goncnullalves, V. Simoes, A.G. De Oliveira, M. Bicho, D. Hans, I. Do Carmo, Male hypogonadism impact in bone quality assessed by trabecular bone score (TBS). Osteoporos. Int. 23, S298-S299 (2012)

101. A.M. Alem, D.J. Sherrard, D.L. Gillen, N.S. Weiss, S.A. Beresford, S.R. Heckbert, C. Wong, C. Stehman-Breen, Increased risk of hip fracture among patients with end-stage renal disease. Kidney Int. 58, 396-399 (2000)

102. J.S. Lindberg, S.M. Moe, Osteoporosis in end-state renal disease. Semin. Nephrol. 19, 115-122 (1999)

103. C.O. Stehman-Breen, D.J. Sherrard, A.M. Alem, D.L. Gillen, S.R. Heckbert, C.S. Wong, A. Ball, N.S. Weiss, Risk factors for hip fracture among patients with end-stage renal disease. Kidney Int. 58, 2200-2205 (2000)

104. E. Leib, D. Stoll, R. Winzenrieth, D. Hans, Lumbar spine microarchitecture impairment evaluation in chronic kidney disease: a TBS study. J. Clin. Densitom. 16, 266 (2013)

105. L. Chapuis, R. Winzenrieth, D. Hans, J.-L. Paitier, In vivo evaluation of genetical hematochromatosis impact on quality bone: a TBS preliminary study. Osteoporos. Int. 24, S323-S324 (2013)

106. W.D. Leslie, B. Aubry-Rozier, O. Lamy, D. Hans, TBS (trabecular bone score) and diabetes-related fracture risk. J. Clin. Endocrinol. Metabol. 98, 602-609 (2013) 